\title{
Inhaltsverzeichnis zu Band III
}

\section{Anhang und Register}

Anhang (Anh) Gesetzestexte . . . . . . . . . . . . . . . 2323

Inhaltsübersicht . . . . . . . . . . . . . . . . . . . . . . . . . 2323

Vorbemerkung . . . . . . . . . . . . . . . . . . . . . 2329

I. Allgemeines (Anh 1 ff.) . . . . . . . . . . . . . . . . . . . . . 2329

II. Gleichberechtigungsgesetz (Anh 17) . . . . . . . . . . . . . . . 2348

III. Rechtspflegergesetz (Anh 18) . . . . . . . . . . . . . . . . . . 2371

IV. Grundbuchumschreibung auf den neuen Vordruck (Anh 19ff.) . . . . 2377

V. Anerbenrecht (Anh 43 ff.) . . . . . . . . . . . . . . . . . . . . 2425

VI. Landwirtschaftliche Entschuldung (Anh 62,63) . . . . . . . . . . 2457

VII. Flurbereinigungsgesetz (Anh 64) . . . . . . . . . . . . . . . 2460

VIII. Bodenschätzung, Liegenschaftskataster und Grundbuch (Anh 65ff.) 2469

IX. Wohnungseigentum (Anh 77ff.) . . . . . . . . . . . . . . . . . 2491

$\mathrm{X}$. Gesetz über die Sicherung der Bauforderungen (Anh 90) . . . . . 2514

XI. Siedlungsgesetz (Anh 91 ff.) . . . . . . . . . . . . . . . . . . 2525

XII. Heimstätte (Anh 94, 95) . . . . . . . . . . . . . . . . . . . . . 2528

XIII. Landarbeiterwohnungen und -eigenheime (Anh 96, 97) . . . . . . 2539

XIV. Währungsreform und Lastenausgleich (Anh 98 ff.) . . . . . . . . . 2542

XV. Steuern (Anh 104ff.) . . . . . . . . . . . . . . . . . . . . . 2566

XVI. Kostenordnung (Anh 113) . . . . . . . . . . . . . . . . . . . 2587

XVII. Sowjetzone (Anh 114) . . . . . . . . . . . . . . . . . . . . . 2606

Ergănzungen und Berichtigungen (ErgVerz) . . . . . . . . . . . . . . 2613

zu AbkVerz usw . . . . . . . . . . . . . . . . . . . . . . . . . . . 2613

$\mathrm{zu} G T$-Teil . . . . . . . . . . . . . . . . . . . . . . . . . . . . . 2613

zur Einleitung $(E)$. . . . . . . . . . . . . . . . . . . . . . 2621

zur Kommentierung . . . . . . . . . . . . . . . . . . . . . . . . . 2643

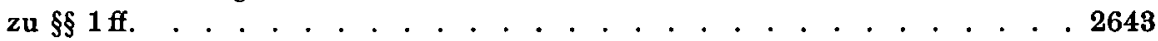

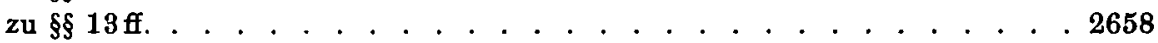

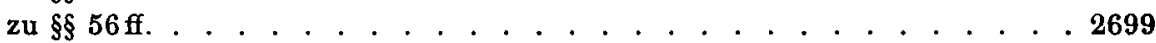

$\mathbf{z u} \S \mathbf{7 1 \mathrm { ff }}$. . . . . . . . . . . . . . . . . . . . . . . . . . . . 2700

$\mathrm{zu} \S 82 \mathrm{ff} . . . . . . . . . . . . . . . . . . . .2701$

Zum Anhang . . . . . . . . . . . . . . . . . . . . . . . . 2703

Allgemeine Hinweise . . . . . . . . . . . . . . . . . . 2703

Gesetzesregister (GesReg) . . . . . . . . . . . . . . . . . . . . 2705

Inhaltsübersicht . . . . . . . . . . . . . . . . . . . 2705

Vorbemerkung .. . . . . . . . . . . . . . . . . . . 2706

I. Hinweise auf in der Einleitung und im Kommentarteil abgedruckte gesetzliche Vorschriften . . . . . . . . . . . . . . . 2706

1. Bundesrecht, Besatzungs- und Zonenrecht. . . . . . . . . . . . 2706

2. Landesrecht. . . . . . . . . . . . . . . . . . . 2708 


\section{Inhaltsverzeichnis}

II. Hinweise auf wichtige besprochene grundbuchrechtliche Vorschriften . 2709

1. GBOÄndVO $(G T 2)$. . . . . . . . . . . . . . . . . . . . . 2709

2. GBOAVO $(G T 4)$. . . . . . . . . . . . . . . . . . . . . . 2709

3. GBVerfgg $(G T 5)$. . . . . . . . . . . . . . . . . 2710 Anlagen dazu $(G T 6 f$.$) . . . . . . . . . . . . . . . . . 2716$

4. GBOGeschO $(G T 16)$. . . . . . . . . . . . . . . . . . . . 2717

5. Ausfertigung der Hy pothekenbriefe usw $(G T$ 17, 18) $\ldots$. . . . . 2719

6. Grundbuch und Kataster $(G T 19 f$.$) . . . . . . . . . . . . . . 2719$

7. Grundbuch und Wohnungseigentum $(G T 32 f$.$) . . . . . . . . 2721$

8. Aktenordnung $(G T 41 f$.$) . . . . . . . . . . . . . . . . . 2722$

9. FGG $(G T$ 45) . . . . . . . . . . . . . . . . . . . . . . . . . 2723

10. Baden-Württemberg $(G T 46 f$.$) . . . . . . . . . . . . . . . . 2724$

11. Bayern DA . . . . . . . . . . . . . . . . . . . . . . . . . 2729

III. AV RJM zum Grundbuchrecht . . . . . . . . . . . . . . . . . 2735

Sachregister (alphabetisch) . . . . . . . . . . . . . . . . 2738 